\title{
Pregnancy and perinatal outcomes after assisted reproduction: a comparative study
}

\author{
E. S. Sills • D. J. Walsh · A. P. H. Walsh
}

Received: 21 October 2008/Accepted: 22 October 2008/Published online: 20 November 2008

(C) Royal Academy of Medicine in Ireland 2008

\section{Dear Editor,}

We welcomed the paper by Allen et al. [1] which provides reassurance about the rate of congenital malformations in babies delivered after assisted reproductive technology (ART). Their data are in close agreement with previous research [2], where an increased risk of placenta previa after in vitro fertilisation (IVF) was identified. As Allen et al. note, however, the true incidence of stillbirth and miscarriage after IVF remains unknown, because the scope of their investigation did not include all IVF pregnancies (i.e., only deliveries known to have good perinatal outcomes were sampled).

While their study did achieve a questionnaire return rate of $65 \%$ from these parents of IVF children, the study design could not identify common demographic or clinical characteristics among the non-responders. From a public health perspective, information on this important sub-group of IVF patients would be highly informative.

As Allen et al. [1] correctly note, the impact of IVF on the course of pregnancy is not yet fully understood. For example, anecdotal reports of mature stillbirths in IVF patients who go beyond 40 weeks gestation have been frustrating to assess systematically. It is hoped that future epidemiologic studies will address this issue. In the meantime, we agree with others $[3,4]$ that in the absence of standardised protocols for the obstetric management of pregnancies conceived with IVF, it is prudent for such gestations to be regarded as high-risk.

\section{References}

1. Allen C, Bowdin S, Harrison RF et al (2008) Pregnancy and perinatal outcomes after assisted reproduction: a comparative study. Ir J Med Sci 177:233-241. doi:10.1007/s11845-008-0172-9

2. Romundstad LB, Romundstad PR, Sunde A et al (2006) Increased risk of placenta previa in pregnancies following IVF/ICSI; a comparison of ART and non-ART pregnancies in the same mother. Hum Reprod 21:2353-2358. doi:10.1093/humrep/del153

3. Ombelet W, Martens G, De Sutter P et al (2006) Perinatal outcome of 12, 021 singleton and 3108 twin births after non-IVF-assisted reproduction: a cohort study. Hum Reprod 21:1025-1032. doi: 10.1093/humrep/dei419

4. Kapiteijn K, de Bruijn CS, de Boer E et al (2006) Does subfertility explain the risk of poor perinatal outcome after IVF and ovarian hyperstimulation? Hum Reprod 21:3228-3234. doi:10.1093/ humrep/del311
E. S. Sills $(\bowtie) \cdot$ D. J. Walsh · A. P. H. Walsh

The Sims Institute/Sims International Fertility Clinic,

Rosemount Hall, Dundrum Road, Dundrum, Dublin 14, Ireland

e-mail: drscottsills@sims.ie 